\title{
Biological activities of collagen peptides obtained by en- zymic Hydrolysis from Far-Eastern holothurians
}

\author{
Popov A. ${ }^{1,2, ~ *}$, Artyukov A. ${ }^{1}$, Krivoshapko O. ${ }^{1}$, Kozlovskaya E. ${ }^{1}$ \\ ${ }^{1}$ G. B. Elyakov Pacific Institute of Bioorganic Chemistry Far Eastern Branch, Russian Academy of Sciences, Vladivostok, Russia \\ ${ }^{2}$ Far Eastern State University, Vladivostok, Russia
}

Email address:

popovam@piboc.dvo.ru(Popov A.)

\section{To cite this article:}

Popov A., Artyukov A., Krivoshapko O., Kozlovskaya E. Biological Activities of Collagen Peptides Obtained by Enzymic Hydrolysis from Far-Eastern Holothurians. American Journal of Biomedical and Life Sciences. Vol. 1, No. 1, 2013, pp. 17-26.

doi: 10.11648/j.ajbls.20130101.14

\begin{abstract}
The certain sea cucumbers are the marine animals which are important as human delicacy food source. In addition a number of unique biological and pharmacological active compounds have been ascribed to various species of sea cucumbers. In current work the collagen peptides (CPs) from the bodies of the far-eastern holothurians (sea cucumber) Apostichopus japonicus and Cucumaria japonica by treated with a complex of proteolytic enzymes from Kamchatka crab Paralithodes camtschaticus were obtained, and the antitumor, anticoagulant, anti-inflammatory, and wound healing properties these CPs were estimated. The element and amino acid analysis of CPs from trepang and cucumaria are suggested that it's could be regarded as a typical collagen fragments containing $6 \%$ sulfated carbohydrate and/or amino acid residues. CPs inhibited growth and progression solid Erlich tumor, but not in alike degree. Our results clearly showed, that these CPs possessed the moderate anticoagulant activity, and are preferential inhibitors of the initial link of the blood coagulation system. We also determined that the CPs revealed significant wound healing effect in regarding to thermal wounds and have high anti-inflammatory activity by used carrageenane model of acute inflammatory. Apparently, that the degree of biological activity depend on characteristics of amino acid composition and concentration of CPs. Taken together, these results indicate that CPs from sea cucumbers have similar to biological activities with other collagen peptides (components of the extracellular matrix, endostatin and others) and sulfated polysaccharides. We proposed that the obtained CPs may be applied as components functional food and nontoxic remedies of supplementary therapy for prevention and treatment of various diseases.
\end{abstract}

Keywords: Bioactive Peptides, Collagen Peptides, Sea Cucumber, Marine Drugs, Functional Food, Biological Activity

\section{Introduction}

In recent decades, sea cucumbers have gained popularity among researchers not only due to their nutritive value, but also due to their potential health benefits and therapeutic uses. There are several research groups engaged in conducting preliminary studies on immunomodulatory, antiangiogenic, anticoagulant, anticancer, angiotensin-I-converting enzyme inhibitors, antiinflammatory and antitumor, etc., activities of the sea cucumbers. Abundance of biological active substances, isolated from sea cucumber, such as triterpene glycosides (saponins), chondroitin sulfates, lectins, heparin, cerberosides, ganglosides, sterols and omega- 6 omega- 3 fatty acid, and also protein hydrolyzates and bioactive peptides, have shown multiple useful pharmacological effects [1-6].
Fragments of food proteins containing sequences of bioactive peptides could exert a physiological effect in the body. These short chains of amino acids are inactive within the sequence of the parent protein, but can be released during gastrointestinal digestion, food processing, or fermentation. The many bioactive peptides were obtained by enzymatic hydrolysis of collagen proteins, and broad spectrum curative activities of collagen peptides ( $\mathrm{CPs})$ was determined $[7,8]$.

In recent fifteen years, the products of enzymatic transformation of some human collagens have attracted the attention of researchers with their significant antitumor activities. It has been established that a prolonged exposure to endostatin, the C-terminal fragment of human collagen XVIII, inhibits, through induction of apoptosis of endothelial cells, the growth of blood vessels that feed tumors 
and create the conditions for metastasis of their cells. After the treatment, tumor development is not renewed; this condition of a tumor is called "sleeping." The pronounced antiangiogenic properties of endostatin allow used to treat collagen proteins as potential agents for a new approach to the treatment of tumors [9]. The prospects of their use can be the development of a combination therapy with cytostatics that directly inhibit growth and division of tumor cells [10].

In medical practice, for prevention of thromboembolic complications in cancer patients subject to the risk of developing cardiovascular insufficiency, heparin, a polysaccharide of animal origin with a high degree of sulfanation, is widely used as anticoagulant and antithrombogenic medication. The effect of heparin on the development and metastasis of tumors remains unclear; numerous clinical data are extremely contradictory [11]. In addition, heparin has certain limitations and side effects, such as the emergence of drug dependence, allergies, and thrombocytopenia. Research is being conducted on the possibility of using other natural compounds, for example sulphated polysaccharides and peptides, whose anticoagulant and thrombolytic effects are comparable to the effects of heparin, as anticoagulants; they also possess and other useful activities. In this respect, fucoidans from marine brown algae [12], heparinomimetics from marine shrimp [13], glycosaminoglycans [14], and echinoderms-derived CPs [8] revealed the antithrombotic effects, and some of them can be of interest as potentially perspective anticoagulating agents.

Most diseases have an underlying etiology involving inflammation. Inflammation becomes a problem is when the actual agent is not resolved and the body can't finish up the inflammatory response. Therefore it goes from acute inflammation to chronic is created the problem for health. Bioactive peptides from valuable seafood such as protein hydrolyzates and CPs have protective and correcting influence upon functions of the organism under experimental modeling different pathologies, associated with chronic inflammation $[2,7,8,15,16]$.

CPs, isolated from extracellular matrix, are possessed the regulatory and wound healing properties, specific binding with glycoprotein receptors of these matrix. This mechanism plays the important role at realignment matrix in response to acute inflammation, as well as in case of healing wounds [17]. So, collagenase, isolated from Clostridium histolyticum, assists wound healing. Extracellular matrix degradation by used collagenase is created of bioactive collagen fragments, which can stimulate the cellular reactions, directed on reparations and angiogenesis of damaged tissues [18]. These studies help to understand in molecular mechanisms of the healing wounds, induced and controlled by CPs.

However, in spite of successes, reached in study biologically active CPs from sea hydrobiontes, explored arsenal their pharmacological activities else extremely insufficient. Therefore conduct active searching of new efficient CPs from diverse kinds of seafood by used novel methods it's producing.

We present interesting to research of antitumor, anticoagulant, anti-inflammatory, and wound healing properties of CPs.

At present work we were developed the technology acquisition of collagen peptides from two species of far-eastern commercial holothurians (sea cucumbers) Apostichopus japonicus and Cucumaria japonica that inhabit the Sea of Japan, and biological activities notably antitumor, anticoagulant, anti-inflammatory and wound healing effects these isolated CPs were studied. Interestingly, that these holothurians species are widely used in the Asia-Pacific region, as a delicacy food product, and are applied in medicine, as helpful medical and prophylactic remedies, especially at immunological and oncological diseases [1, 19].

\section{Materials and Methods}

We developed and patented a method (Patent no. 2302250, registered in the Registry of Inventions of the RF on June $10,2007)$ for obtaining polypeptide fragments of collagenic protein from the sea cucumber body with the use of the "Collagenase KK" complex of proteolytic enzymes from the hepatopancreas of the Kamchatka crab Paralithodes camtschaticus (Immunopreparat, Russia) during 3.5-4.5 h at $\mathrm{pH} 7.5$ and a temperature of $35-37^{\circ} \mathrm{C}$. The product of fermentolysis was dissolved in water and precipitated with acid; the precipitate was separated by centrifugation at $3000 \mathrm{rpm}$ for $30 \mathrm{~min}$ and dissolved in $0.05-0.11$ of sodium bicarbonate solution. The obtained solution containing CPs was subjected to dialysis and ultra filtration using a $15 \mathrm{kDa}$ membrane, then sterilized and dried. The end products were lyophilized CPs preparations from the sea cucumbers Apostichopus japonicus and Cucumaria japonica; the preparations were very soluble in water and biological fluids.

The amino acid compositions of CPs from the sea cucumbers were quantified on a Biochrome 30 amino acid analyzer (England). The carbohydrate content of these peptides was measured according to the procedure described by Prange et al. [20].

Mass-spectrometric investigations were performed on a matrix-assisted time of flight mass spectrometer (MALDI-TOF MS, Bruker Biflex III) (Germany) equipped with laser desorption and ionization of the sample. Sinapinic acid (Fluka, $>99 \%$ pure) was used as a matrix. The occurrence of the structure of a native collagen in this preparation was registered by the method of CD-spectroscopy [21].

$\mathrm{CD}$ spectrums of aqueous solutions of the native collagen $(\mathrm{C}=1-2 \mathrm{mg} / \mathrm{ml}$ ) recorded $190-250 \mathrm{~nm}$ in a Jasco J-500A spectrapolarimeter (Japan). The ellipsis in CD-spectrum was measured for a mean amino acid residue by the formula:

$$
[\theta]=[\theta]_{\text {obs. }} \mathrm{S} \times 110 / 10 \mathrm{Cl},
$$

where $[\theta]_{\text {obs. }}$ is the observed value in the CD-spectrum at the given wavelength; $\mathrm{S}$ is the scale of device sensitivity in 
grades; $110 \mathrm{Da}$ is the mean molecular weight of the amino acid residue; $\mathrm{C}$, is the concentration of the $\mathrm{CPs}, \mathrm{mg} / \mathrm{ml}$; and $l$, cuvette thickness, sm.

The content of micro- and macroelements $(\mathrm{S}, \mathrm{K}, \mathrm{Ca}, \mathrm{Fe}$, $\mathrm{Zn}$, and $\mathrm{Br}$ ) was determined by the method of X-ray fluorescence analysis [22]. The presence of sulfate groups in these PCs was confirmed by direct determination of sulfate groups [23].

Investigations with the use of experimental animals were conducted in accordance with the rules of laboratory practice (GLP), the Order No. 267 of Ministry of Health of the Russian Federation of June 19, 2003. On Approval of the Rules of the Laboratory Practice and Instruction on Experimental (Preclinical) Study of New Pharmacological Preparations (2005). The experiments were conducted on pathogenic-free mice of the CD-1 and CBA lines weighing 20 $\pm 2 \mathrm{~g}$ from the Pushchino Nursery for Laboratory Animals and bred in the vivarium of the Pacific Institute of Bioorganic Chemistry (PIBOC, FEB RAS) (Certificate available). The test animals were kept in accordance with the rules accepted by the European Convention for the protection of vertebrates used for experimental and other scientific purposes (Strasbourg, 1986); they were subjected to euthanasia, adhering to the Rules of Conducting Research Using Experimental Animals, approved by the Ministry of Health and Social Development of the Russian Federation.

"Acute" toxicity was tested on white mice and rats using a single intraperitoneal, subcutaneous injection or per oral administration of the preparation. Based on the data of animal death, the $50 \%$ lethal dose was determined $\left(\mathrm{LD}_{50}\right)$ [24].

Evaluation of the antitumor activity of the CPs on ascitic and solid variations of Erlich tumor was performed for allogenic pathogenic-free mice of the CD-1 line [24].

In the case of the solid model, the tumor was transplanted by subcutaneous inoculation by $3 \times 10^{6}$ ascetic tumor cells. The control and test animal groups included 10-12 mice each. The CPs from the sea cucumbers was injected subcutaneously in doses of 10,20 , and $40 \mathrm{mg} / \mathrm{kg}$ at a distance of 3 $\mathrm{cm}$ from the tumor, on day 7 after inoculation and during the following 10 days daily. On day 20, the animals with solid tumors were subjected to euthanasia; the tumors were ablated and weighted. The antitumor effect was estimated by inhibition of tumor growth (ITG, \%) as compared to the control.

Treatment of animals with ascetic tumors began in next day after intraperitoneal transplantation of $5 \times 10^{6}$ tumor cells. The control and test animal groups contained ten mice each. The CPs from the sea cucumbers was injected intraperitoneally in doses of 10,20 , and $40 \mathrm{mg} / \mathrm{kg}$. The antitumor effect was estimated by an increase of the mean life span (LSI, \%) as compared to the control by the formula:

$$
\mathrm{LSI}=(\mathrm{T} / \mathrm{C}) \times 100 \%,
$$

where $\mathrm{T}$ and $\mathrm{C}$ are the average values of life span of laboratory animals in test and control groups, respectively (in days).
The obtained results were processed with the use of the non-parametric criterion of Wilkoxon-Mann-Whitney (U). The differences were significant at $\mathrm{P}<0.05$.

During the study of antiinflammatory activity nonspecific local inflammation was induced by administration $1 \mathrm{mg}$ in saline $(100 \mu \mathrm{l})$ of delta-carrageen type IV (Sigma, USA) for back foot pad of mice CBA weight 19-22 g, as described earlier [25].

Modelling of thermal wounds performed according to [25]. Briefly, for measurement of dimensions to wounds were applied a cover-slips, and on them were copied wound boundaries. The cover-slips with copied wound boundaries were digitized by used the scanner for graphical file. The wound areas were determined by means of Adobe Photoshop CS (version 8.0) program.

An effect of CPs on the system of coagulation haemostasis was assessed in vitro by the following parameters: (1) the coagulation time of whole unstabilized blood; (2) impact on the initial stage of blood coagulation tests for determining prothrombin time and activated partial thromboplastin time (APTT); (3) impact on the final stage of blood coagulation in the test for determination of thrombin time of coagulation of recalcified plasma. To analyze anticoagulation activity, we obtained human thrombocytic plasma, stabilized by injection of $3.8 \%$ sodium citrate solution in a ratio $9: 1$.

The inhibition coefficient of coagulation of whole unstabilized blood of laboratory mice was determined by the relationship of the time of clot formation after addition of the preparations under study to the time of coagulation in the control sample. Prothrombin time was determined in accordance with the recommendations of the kit producer (Tekhnologiya-Standart, Russia) by the time of coagulation of recalcified plasma after addition of a tissue thromboplastin of the specified activity (Tekhnoplastin, Russia). The results are expressed in seconds, and prothrombin index values (PTI, \%). Calculation of the PTI was made by the formula:

$$
\mathrm{PTI}=(\mathrm{A} / \mathrm{B}) \times 100 \%,
$$

where (A) is the known activity of thromboplastin (20 s) and (B) is the protrombin time of the plasma under study.

APTT and thrombin time were determined with the use of a diagnostic kit (Olivex, Russia). The results were expressed in seconds, comparing the blood plasm clotting time in control and test samples. In all the tests for determination of anticoagulation properties, every dose of the preparations was tested at least three to four times.

For comparative assessment of anticoagulation activity CPs from the sea cucumbers, we were used sulfated polysaccharides: sulfated galactan - carrageenan from the red alga Chondrus pinulatus [26], fucoidans 1 and 2 extracted from Fucus evanescens and Laminaria cichorioides, respectively [27], and commercial heparin (ICN, USA) as comparison preparation.

For mathematical processing of the obtained material we used the program Microsoft Excel 7 using variation methods 
in statistics and computing the arithmetic mean (M), mean-square deviation $(\mathrm{C})$, mean error $(\mathrm{m})$ and Student's $t$-test. Normally, $\mathrm{p}<0.05$ was regarded as significantly different. The results were representative at least two to three independent experiments.

\section{Results and discussion}

\subsection{The Physical-Chemical Characteristics of Cps}

Through proteolytic modification of collagen from the Japanese sea cucumbers trepang A. japonicus we obtained a homogenous CPs, owning of different medicinal effects. According to data of MALDI-mass spectrometry, molecular weight of CPs from the trepang is about $12 \mathrm{kDa}$ (Fig. 1). These CPs are referred to as "Apostatin". Similar products of enzymatic proteolysis of collagen proteins from the Far-eastern cucumaria are referred to as preparation " $\mathrm{Cu}$ cumarin". Interestingly, the chromato-mass spectrometric analysis of "Cucumarin" does not show the homogeneous peak of the distribution of CPs on molecular weights.

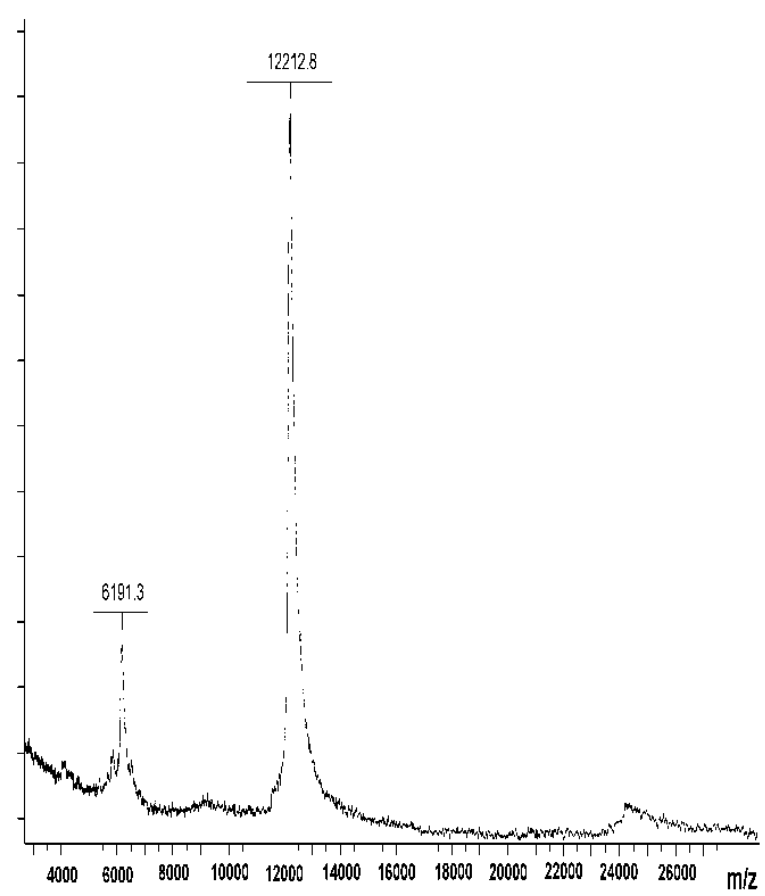

Fig 1. Chromato-mass spectrometric spectrum of CPs from A. japonicus, obtained by fermented proteolysis (preparation designated of "Apostatin"). On axis of the abscissas - ratio of the mass of the ion to charge; on axis of the ordinates - relative intensity of the ion current

CD-spectroscopy showed that the CPs of "Apostatin" and "Cucumarin" preserves the native structure of collagen: this is indicated by the presence in its CD-spectrum of a negative band of a high ellipsis in the region of $200 \mathrm{~nm}$ [21].

The preparation "Apostatin" and has the following chemical composition, in \%: protein, 54.18; monosaccharides, 10.91; ashes, 18.41; sulfates, 6.49; moisture, 7.49; and other components, 2.52 . On results of the element analysis there is good reason to believe that that CPs can contain sulfated carbohydrate and/or amino acid residues [23].

In order to access of structural characteristics of "Apostatin" and "Cucumarin", we examined the amino acid composition these CPs (see Table 1). A comparison of the amino acid composition of the CPs from trepang and cucumaria revealed a higher content of negatively charged amino acids (aspartic and glutamic acids), oxyacids (with a predomination serine and threonine over tyrosine) and an increased content of valine. The CPs from trepang the contents of glycine, hydoxyproline, and proline approximately in 1.5 - 2.0 times more, than CPs from cucucmaria. Thus, element and amino acid analysis of CPs from trepang and cucumaria are suggested that it's could be regarded as a typical collagen fragments containing $6 \%$ sulfated carbohydrate and/or amino acid residues [23].

Table 1. Comparative analysis of the amino acid composition of PCs from trepang and cucumaria (\% by weight)

\begin{tabular}{|c|c|c|}
\hline $\begin{array}{c}\text { Name of amino } \\
\text { acids }\end{array}$ & $\begin{array}{c}\text { CPs of trepang } \\
\text { A. japonicus }\end{array}$ & $\begin{array}{c}\text { CPs of cucumaria } \\
\text { C. japonica }\end{array}$ \\
\hline Aspartic acid & 8.81 & 8.79 \\
\hline Threonine & 4.34 & 4.23 \\
\hline Serine & 4.58 & 4.14 \\
\hline Glutamic acid & 14.72 & 14.69 \\
\hline Hydroxyproline & 6.18 & 3.57 \\
\hline Proline & 9.79 & 6.77 \\
\hline Glycine & 18.17 & 11.37 \\
\hline Alanine & 6.87 & 605 \\
\hline Citrulline & - & 0.31 \\
\hline Valine & 4.92 & 3.67 \\
\hline Methionine & 0.04 & 0.92 \\
\hline Cystine & 0.00 & 0.39 \\
\hline Isoleucine & 2.10 & 3.06 \\
\hline Leucine & 2.89 & 4.45 \\
\hline Tyrosine & 2.22 & 1.74 \\
\hline Phenylalanine & 1.62 & 2.62 \\
\hline Lysine & 3.20 & 3.30 \\
\hline Histidine & 1.12 & 1.04 \\
\hline Arginine & 6.33 & 6.75 \\
\hline
\end{tabular}

Each value expresses the mean from tree determinations. All values are statistically significant $(\mathrm{p}<0.05)$

It is noteworthy that endostatin, a proteolytic fragment of collagen XVIII of mammalians, in contrast to CPs from sea cucumbers, cannot be assigned to typical collagen peptides [9].

\subsection{Toxicit}


Testing of the acute toxicity of the preparation has shown that the collagen protein in aqueous solution has a low toxicity with a single oral $\left(\mathrm{LD}_{50}>3 \mathrm{~g} / \mathrm{kg}\right)$, intraperitoneal, and subcutaneous $\left(\mathrm{LD}_{50}>1 \mathrm{~g} / \mathrm{kg}\right)$ injection to rats and mice.

\subsection{Antitumor Activity}

Tumoral diseases - the burning issue of modern health care as are one of the leading causes of death in the world. According to WHO data the cancer cases for the last 25 years grew by 1.5-2.0 times. For various versions of a cancer one common feature - these diseases extremely difficultly to cure is characteristic. It is necessary to recognize that the cancer therapy very expensive and is rather ineffective now. At the same time it is considered that to $40 \%$ of cases of diseases of a cancer it is possible to prevent by means of the healthy food allowance containing natural cancer-preventive and antineoplastic drugs notably bioflavonoids, antioxidants, peptides and other natural components.

Sea cucumbers contain a variety of antitumor ingredients. These antitumor active components are possessed of inhibitory action in different stages of tumor development, progression and metastasis. The exploration of antitumor active ingredients from sea cucumbers might open windows of opportunities to discover new antitumor agents from other marine sources for clinical tumor treatment [1, 5].

In this context, products of fermentative transformations collagen proteins already long ago attract attention of the researchers of significant antitumor activity. So, is installed that long influence C-terminal fragment of human collagen XVIII - endostatin causes apopotosis of endotelialic cells and inhibited the growing of the blood vessels, supplying tumor and creating condition for metastasis its cells [9]. Expressed antiangiogenic properties of endostatin allow considering some PCs as potential agents at treatment of the tumors. The prospects of the use PCs are concluded in use them in multifunction therapy simultaneously with cytostatics, inhibiting growth and division of tumor cells [10].

By used of enzyme proteolytic complex "Collagenase KK" from crab Paralithodes camtschaticus, us are a success to isolated CPs from trepang "Apostatin" and cucumaria "Cucumarin" throughout were studied of antitumor properties.

In a series of experiments on the study of the antitumor activity of the "Apostatin" in vivo, we found its optimal therapeutic doses with respect to solid and ascitic variations of Ehrlich tumor. It was found that in doses from 10 to 40 $\mathrm{mg} / \mathrm{kg}$ the "Apostatin" exerts a dose-dependent inhibitory effect on the growth of solid tumors. The average tumor mass in the control group was almost two times higher $(P<$ $0.05)$ than in the experimental groups of mice that received a course of therapy with the tested CPs at a dose of $20 \mathrm{mg} / \mathrm{kg}$. The values of average tumor mass were $1252 \pm 234 \mathrm{mg}$ in the control and $698 \pm 125 \mathrm{mg}$ in the experimental group.
It should be noted that in experiments on the solid rat model of the Walker 256 carcinosarcoma, "Apostatin" injected intraperitoneally for 7 days at $20 \mathrm{mg} / \mathrm{kg}$ significantly $(P<0.05)$ enhanced the antitumor and antimetastatic effects of the well-known cytostatic drug cyclophosphan [28].

"Cucumarin" also in dose $40 \mathrm{mg} / \mathrm{kg}$ were exerted of positive inhibitory effect on the growth of solid Ehrlich tumor: inhibition growth tumor was $34.2 \pm 4.8 \%$, when compared to the non-treated group $(P<0.05)$

In the case of the ascitic Ehrlich tumor, "Apostatin" preparation was less efficient. Over ten courses of treatment, it caused a significant $(P>0.05)$ increase in average longevity by $29.4 \pm 3.2 \%$ compared to the controls only at 40 $\mathrm{mg} / \mathrm{kg}$. "Cucumarin" preparation in doses from 10 to 40 $\mathrm{mg} / \mathrm{kg}$ was not active in conditions these experiments.

The results of our study of the CPs from trepang ("Apostatin" preparation) and cucumaria ("Cucumarin" preparation) are in good agreement with numerous data on endostatin and various sulfated polysaccharides, which generally display only a slight or no inhibiting effect against ascitic tumors. This is likely to be related to the predominantly antiangiogenic effect of the above compounds on the growth of solid tumors $[9,10,13]$.

\subsection{Anticoagulant Activity}

Study of the anticoagulant properties of the CPs from $A$. japonicus showed that its addition to nonstabilized murine blood in doses greater than $25 \mu \mathrm{g} / \mathrm{ml}$ caused an increase in its clotting time (maximum at $63.1 \pm 3.2 \mu \mathrm{g} / \mathrm{ml}$ ). The same effect was observed with the addition of $0.035 \mathrm{ME} / \mathrm{ml}$ or 1.4 $\pm 0.2 \mu \mathrm{g} / \mathrm{ml}$ heparin, indicating the moderate anticoagulant activity of the CPs from trepang ("Apostatin" preparation).

Following the addition of tissue thromboplastin to stabilized human thrombocyte plasma, which triggers the external pathway of blood clotting, the anticoagulant effect of "Apostatin" preparation was already recorded at $0.1 \mathrm{mg} / \mathrm{ml}$ $(\mathrm{PTI}=64.2 \pm 4.3 \%)$ and activity was further increased at 0.4 $\mathrm{mg} / \mathrm{ml}$. Similar values of anticoagulant activity were found for CPs from the cucumaria and a sulfated polysaccharide fucoidan 1 (Fig. 2a). The effect of fucoidan 2 from the brown alga $L$. cichorioides was comparable to that of heparin, and at a dose of $0.4 \mathrm{mg} / \mathrm{kg}$, fucoidan 2 completely prevented blood clotting.

For comparison between the tested CPs and other preparations, blood coagulation by the internal mechanism induced in the organism on contact of the blood with the subendothelium was assessed in the APTT test by adding kaolin as a foreign surface to the plasma. At $0.4 \mathrm{mg} / \mathrm{ml}$, all the tested compounds caused a reduction by more than $3 \mathrm{~min}$ in the plasma clotting time (Fig. 2b). A fourfold decrease in the dose of "Apostatin" reduced its anticoagulant activity, as was also the case with polysaccharides, carrageenan, and fucoidan 1. Following the addition of $0.1 \mathrm{mg} / \mathrm{ml} \mathrm{CPs} \mathrm{the}$ recalcification plasma clotting time increased $2.7 \pm 0.3$ times, compared to the normal plasma. As in the previous experiment, similar dynamics of anticoagulant activity in relation 
to the dose were found for "Apostatin" and fucoidan 1, as well as heparin and fucoidan 2 . We note that the effect of "Cucumarin" on blood clotting in the APTT test was comparable to that of the "Apostatin" (Fig. 2b).

The thrombin time test (Fig. 2c), which measures the final stage of plasma clotting, showed that only sulfated polysaccharides at a dose of $0.4 \mathrm{mg} / \mathrm{ml}$ had an inhibitory effect on the formation of a fibrin clot. CPs preparations from the sea cucumbers $A$. japonicus and $C$. japonica showed no significant activity $(P>0.05)$.

(a)

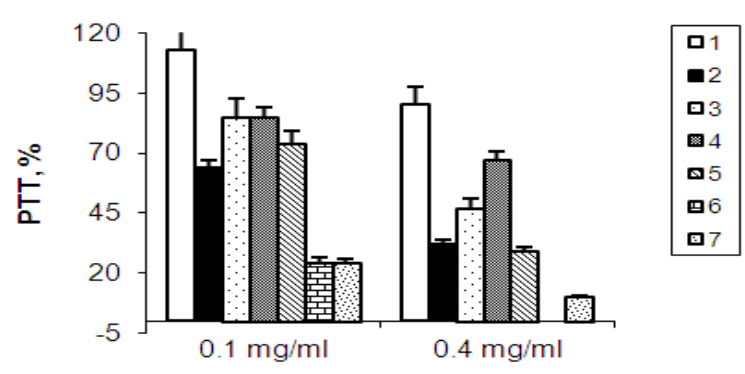

(b)

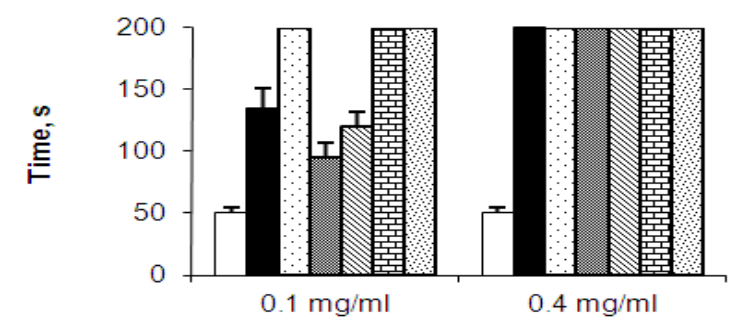

(c)

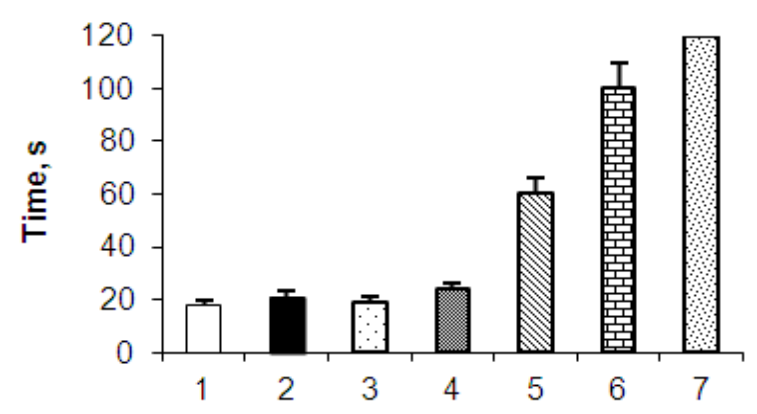

Fig 2. Comparative study of collagen peptides and sulphated polysaccharides on coagulatory hemostasis system in tests: (a) - protrombinic time, in \%, (b) - activated partial thromboplastinic time, in seconds, (c) - trombinic time, seconds: 1 - Control; 2 - "Apostatin"; 3 - "Cucumarin"; 4 carrageenan; 5 -fucoidan-1; 6-fucoidan-2; 7 - heparin. In case (c) dose all preparation studied was $0.4 \mathrm{mg} / \mathrm{ml}$. All values were determined as described in Section 2. Columns, mean of tree independent experiments; bars, $S D$.

These results clearly indicate that the disturbance of blood plasma clotting observed in the three basic tests with the addition of heparin and fucoidans is not characteristic of "Apostatin" and "Cucumarin" preparations.
As opposed to sulfated polysaccharides, which block predominantly activated factors of the internal clotting way and substantially amplify the effect antithrombin factor III, "Apostatin" and "Cucumarin" did not inhibit the enzymatic activity of thrombin and, consequently, the formation of the fibrin thrombus.

It should be noted that other presently known antithrombogenic agents of a protein nature, viz., hirudin and its derivatives, possess a high affinity and high specificity to thrombin and are its direct inhibitors [29].

We emphasize that in contrast to "Apostatin" (Fig. 1), "Cucumarin" displays no clear protein peak but possesses a similar anticoagulant activity. The degree of expression of anticoagulant activity of the investigated agents increases in the following order: carrageenan < "Apostatin" and " $\mathrm{Cu}$ cumarin" $\leq$ fucoidans $<$ heparin.

The peculiarities of the anticoagulant and antitumor effects of "Apostatin" and "Cucumarin" may be due to the presence in its structure of negatively charged sulfated residues, whose physiological importance for different compounds is confirmed by the literature data [13]. An increased degree of sulfation is accompanied by a significant enhancement of their antiangiogenic and anticoagulant activities [30].

Anticoagulant and antitumor activities, the presence of sulfated groups in their structures, and their low toxicity may suggest a similar mechanism of biological activity of "Apostatin" and "Cucumarin" to that of sulfated polysaccharides and the product of proteolytic transformation of collagen XVIII, viz., the protein endostatin. By its chemical structure, collagen XVIII belongs to heparan sulfate proteoglycans, which contain highly sulfated carbohydrate chains sensitive to heparinase [31]. It is therefore quite likely that endostatin has sulfated carbohydrate residues in its structure and possesses anticoagulant activity. The anticoagulant properties of sulfated macromolecules depend on the structural features of their chains: carbohydrate composition, degree of sulfation, distribution and density of charge, as well as size and the level of branching [30, 32]. However, endostatin, as well as sulfated polysaccharides, possess a far broader spectrum of biological activity. With acute toxicity at a dose of over $500 \mathrm{mg} / \mathrm{kg}$ and weak cytotoxicity to tumor cells in vitro, these compounds display pronounced antitumor, antimetastatic, and antiangiogenic activities $[10,13]$. We suppose that CPs from trepang and cucumaria having sulfated carbohydrate and/or amino acid residues in its molecule structure combines the properties of both the protein endostatin and sulfated polysaccharides in its biological activity.

Our findings are in agreement with recent reports, showing the antithrombotic effects of sea cucumber-derived glycosaminoglycan (GAG) [14]. The function of GAG is analogous to dermatan sulfate, both in terms of efficacy and mechanism of antithrombotic action. Furthermore, it has been shown that colt lysis by GAG is controlled by its capacity to enhance plasmin activity, in order to inhibit the 
polymerization of fibrin monomer, consequently altering the fibrin network architecture. It can be claimed that such an effect on human umbilical vein endothelial cells materializes at a transcriptional level and thus might be responsible for the antithrombotic attributes of GAG. The findings of this study suggest that sea cucumber-derived GAG possesses anticoagulant activity in vivo and can be used as a promising drug for antithrombotic therapy [14].

Quite reasonable question - whether keep these CPs from sea cucumbers, obtained by fermentative decomposition of collagen proteins, of anticoagulant properties in tests in vivo at peritoneal, intramuscular and per os the modes of introduction?

We was shown, that the action "Apostatin" on blood coagulability under administration per os was dependent from on introduced concentrations and time to exposition. When "Apostatin" was introduced per os in doses from 25 to $200 \mathrm{mg} / \mathrm{kg}$ take place quick assimilation of this preparation into blood experimental animals (mice). The accounting index anticoagulant activities "Apostatin" (ratio of blood coagulation time in experienced tests to control) in introduced per os in doses 50 and $100 \mathrm{mg} / \mathrm{kg}$ to average approximately 1.5 and 2.0 , correspondingly. It should be noted that anticoagulant activity "Apostatin" at intraperitoneal and intramuscular routs of administration is more expressing, than at per os.

Thereby, "Apostatin" in vivo at administration per os possesses the moderate anticoagulant activity. This fact suggest that under absorption "Apostatin" passing through system of the gastrointestinal tract not be subjected to digestion saving their own anticoagulant properties that it is very important for potential remedies and active components of the functional food.

\subsection{Anti-Inflammatory Activity}

Antiinflammatory activity of CPs was estimated by using carrageenane model of footpad edema, the convenient method for assessing inflammatory responses to irritants. Typically, test compounds are assessed for acute anti-inflammatory activity by examining their ability to reduce or prevent the development of carrageenan-induced paw swelling. This model has long been used to assess the anti-inflammatory properties of agents such as nonsteroidal anti-inflammatory drugs that inhibit prostaglandin production.

In series of experiments were studied CPs preparations "Cucumarin" and "Apostatin" in compared to well-known nonsteroidal anti-inflammatory drug by indametacin. The results obtained are shown in table 2 .

"Cucumarin" and "Apostatin" at peritoneal administration in doses 10 and $20 \mathrm{mg} / \mathrm{kg}$ are possessed quite high anti-inflammatory activity: they inhibit of process formation padfoot edema in the range $30-47 \%$, but preparation of indometecin (in dose в $10 \mathrm{mg} / \mathrm{kg}$ ) in $52.0 \pm 4.06 \%$, by compared with c control. In dose $10 \mathrm{mg} / \mathrm{kg}$ highest activity was shown for preparation "Cucumarin" (approximately $46 \%)$.

Table 2. Antiinflammatory effect of CPs from sea cucumbers by modeling of acute inflammation

\begin{tabular}{cccc}
\hline $\begin{array}{c}\text { Group } \\
\text { (number } \\
\text { of animals) }\end{array}$ & $\begin{array}{c}\text { Dose, } \\
\mathbf{m g} / \mathbf{k g}\end{array}$ & $\begin{array}{c}\text { Weight feet, } \\
\left(\times \mathbf{1 0}^{-2} \mathbf{g}\right)\end{array}$ & $\begin{array}{c}\text { Slowing inflam- } \\
\text { mation, \% }\end{array}$ \\
\hline Control (4) & & $81.25 \pm 1.70$ & - \\
"Indomethacin”(4) & 10 & $39.02 \pm 2.08$ & $52.0 \pm 4.06$ \\
“Cucumarin" (4) & 10 & $43.75 \pm 1.0$ & $46.15 \pm 2.09$ \\
“Cucumarin" (4) & 20 & $55.25 \pm 5.01$ & $32.04 \pm 6.06$ \\
“Apostatin" (4) & 10 & $48.78 \pm 3.20$ & $40.0 \pm 4,09$ \\
“Apostatin" (4) & 20 & $53.25 \pm 1.25$ & $34.46 \pm 2.47$ \\
\hline
\end{tabular}

Note: Abbreviations. "Cucumarin" - CPs from Cucucmaria japonica, "Apostatin" - CPs from Apostichopus japonicus. Each value expresses the mean \pm S.D. from two independent experiments.

It should be noted that in certain cases dose $20 \mathrm{mg} / \mathrm{kg}$ as the result to lesser protective effect, then dose $10 \mathrm{mg} / \mathrm{kg}$, that suggest necessity further study of antiinflammatory potential of tested CPs preparations with used the lower medical doses.

Thus, preparations "Cucumarin" and "Apostatin" from indicated above sea cucumbers species at peritoneal route of administration possess pharmacologically apparent of antiinflammatory activity reducing the development of carrageenan-induced paw swelling in mice.

In recent study was found [16], that the marine oligopeptide preparation (MOP) obtained from Chum Salmon (Oncorhynchus keta) by the method of enzymatic hydrolysis, to possess a radioprotective property through stimulation of the radiation-induced immunosuppression. MOP significantly increased the white blood cell counts after irradiation, and decreased the radiation-induced oxidative damage. These effects may be caused by augmentation of the activities of antioxidant enzymes, such as superoxidedismutase and glutathioneperoxydase, reduction of the lipid peroxidation (malonic dialdehyde level) in liver, and protection against radiation-induced apoptosis. Therefore, authors propose that MOP be used as an ideal antioxidant to alleviate radiation-induced oxidation damage in cancer patients [16].

Earlier also was reported [5] that sea cucumbers contains polyphenol compounds, possessing expressed free radical scavenger and antiinflammatory activities. So, aqueous extract derived from sea cucumbers (Holothuria leucospilota, Holothuria scabra, Stichopus chlorontus) contain significantly higher amounts of total phenolics (4.85-9.70 mg gallic acid equivalent (GAE)/g dw) than the organic extracts (1.53-2.90 mg GAE/g dw). Similarly, total phenols and flavonoids contents in different parts including digestive tract, gonads, muscles, and respiratory apparatus of sea cucumber, Cucumaria frondosa, varied from 22.5 to 236.0 $\mathrm{mg} \mathrm{GEA} / \mathrm{g} \mathrm{dw}$, and 2.9 to $59.8 \mathrm{mg}$ rutin equivalent $/ \mathrm{g} \mathrm{dw}$, respectively. 
We are justified to consider that CPs from sea cucumbers A. japonicus and C. japonica make up collection of antiinflammatory agents from marine sources of raw materials, and specifically from sea cucumbers.

\subsection{Wound Healing Activity}

Preparations CPs, including so-called peptides of sea collagens, is widely used in cosmetology as effective rejuvenating remedies which supports balance of moisture in skin and supplies it with necessary amino acids.

Sea cucumber and sea cucumber-based products are now becoming available in shelves of health food stores due to their therapeutic effects, in particular the wound healing functions (to speed recovery of sores, cuts and wounds on the skin, as well as internally for ulcers and other ailments that involve internal damage). It is believed that direct use of sea cucumber can reduce wound recovery time and help new tissue formation and regeneration in human just as the sea cucumber's ability to quickly regenerate its own body tissue when damaged [33].

It is evident that sea cucumber (Stichopus chloronotus) fatty acids including arachidonic acid (AA C20:4), eicosapentaenoic acid (EPA C20:5), and docosahexaenoic acid (DHA C22:6) can play a potential role in tissue repair and wound healing [34]. It has been revealed in the literature that the bottom sediment feeder sea cucumber can contain high contents of branched chain fatty acids to assist in the potential wound healing activity. An appreciable amount of EPA in sea cucumbers might be linked well with the ability of these echinoderms to initiate tissue repair. EPA is known to be the main active compound in fish oils, and exerts its function by means of prostaglandin inhibition and antithrombic attribute. Besides, EPA also plays a potential role in the mechanism of blood-clotting [34].

As showed recent pilot studies on animal and cellular models [18], the CPs received as a result of fermentative action of a collagenase from a bacterium of $C$. histolyticum, possess a unique combination of wound healing and regulatory activity. They promote restoration of endothelium cages and ceratinocytes at their damage of in vitro, and also to healing of wounds of in vivo. The specified fragments promote fast regeneration an endothelium and accelerate replacement of microvessels. According to authors, degradation of proteins matrix a collagenase leads to formation of bioactive fragments - "matrikins" which can sharply stimulate cellular reactions at injury of skin and process angiogenesis that allows understanding molecular mechanisms of healing of the wounds regulated and induced by CPs.

Considering this fact, we estimated the wound healing potential of CPs from 2 species of sea cucumbers. Testing of wound healing activity of creams, containing as active components these CPs was carried out on non-pathogen mice females of the line CBA to whom put thermal wounds. The commercial cream "Methyluracyl" used as a preparation of comparison.
Results are given in table 3 . From analysis the data provided in the table, it is apparently that "Cucumarin" and "Apostatin" (1\% preparations) as medicinal components of cream possesses the expressed wound healing action, reducing time of healing of wounds. Especially clear distinctions in wound healing activity between studied groups were noted for the 7th day after induction of thermal burns. As showed the experiment, the greatest efficiency $1 \%$ preparation "Apostatin", which was designed on the basis of children's cream had the expressed healing effect $(85.4 \pm 7.1 \%)$ on thermal burns. The wound healing effects of the $1 \%$ preparation "Cucumarin" $(80.3 \pm 7.8 \%)$ and commercial medicinal cream "Methylurasyl" (70.2 $\pm 6.2 \%)$ also were much higher than control $(48.5 \pm 4.2 \%)$. Our results clearly demonstrated that "Cucumarin" and "Apostatin" creams exhibited potent wound healing activity that conformed of facts, obtained about some others of CPs.

Table 3. Wound healing activity of the peptides of collagen starfish P. pectinifera

\begin{tabular}{|c|c|c|c|}
\hline \multirow{2}{*}{$\begin{array}{c}\text { Group } \\
\text { of animals }\end{array}$} & \multicolumn{3}{|c|}{ Healing of thermal burns, $\%(m \pm \sigma)$} \\
\hline & 7 days & 9 days & 11 days \\
\hline $\begin{array}{c}\text { Control - } \\
\text { "Baby cream" }\end{array}$ & $48.5 \pm 4.2$ & $70.6 \pm 6.9$ & $87.4 \pm 1.2$ \\
\hline $\begin{array}{l}\text { "Methyluracyl" - } \\
\text { medicinal cream }\end{array}$ & $70.2 \pm 6.2$ & $84.8 \pm 1.4$ & $97.8 \pm 1.3$ \\
\hline $\begin{array}{c}\text { "Apostatin" }(1 \% \\
\text { cream) }\end{array}$ & $85.4 \pm 7.1$ & $92.0 \pm 2.1$ & 100 \\
\hline $\begin{array}{c}\text { "Cucumarin" } \\
\text { cream) }\end{array}$ & $80.3 \pm 7.8$ & $88.2 \pm 2.0$ & $98.8 \pm 0.3$ \\
\hline
\end{tabular}

Each value expresses the mean \pm S.D. from tree dependent experiments.

So, as was shown the researches of the American scientists, the collagenase isolated from $C$. histolyticum, promotes healing of wounds. Degradation extracellular matrix by use of a collagenase creates bioactive fragments which can stimulate the cellular reactions directed on a reparation and angiogenesis. For check of this hypothesis authors carried out limited fermentative hydrolysis of extracellular matrix, occurring of certain capillary endothelium, using the human or bacterial collagenases. Application of a method of an immunopretsipitation with the antibodies which are identified collagen I, II, III, IV and V. The subsequent application of a method of mass spectrometry allowed to define presence of unique fragments degraded matrix. These fragments were formed processed by bacterial, but not by a human collagenase. The specified fragments favor to fast healing an endothelium and accelerate replacement of microvessels in vitro. Collagen IV fragments, fibrillin-1, tenascin, and new peptides with yet not established structure possess the expressed proangiogenic properties. The peptides used in doses from 10 to $100 \mathrm{nmol}$, increase the speed of cellular proliferation microvascular an endothelium by $47 \%$, and angiogenesis in vitro to $200 \%$ in comparison with control. These researches help to understand molecular mechanisms of healing of the wounds regulated and induced by peptides [18]. Therefore, some CPs after 
additional researches can be recommended as an effective wound healing components when developing new medicals and cosmetics.

\subsection{Conclusion}

Thus, the collagen preparations obtained from the sea cucumbers $A$. japonicus and $C$. japonica by enzymatic proteolysis has broad spectrum of biological activities. These CPs are nontoxic, absorbency, safe when applied for long periods of time and has positive organoleptic properties. It can provide the basis for the development of medicinal preparations, as well as biologically active food additives as prophylactic and supplementary therapeutic agents against different diseases.

Clinical applications of many bioactive peptides and CPs are severely not limited main drawbacks such as instability, low solubility, poor bioavailability and rapid metabolism. Multifarious nanotechnology-based delivery approaches have been used to enhance the oral bioavailability, biological activity or tissue-targeting ability of CPs.

On our opinion, there is a great potential to utilize studied CPs from sea cucumbers to develop new remedies and valuable functional foods with physiological benefits for human beings.

\section{Acknowledgments}

The authors are grateful to N.M. Shevchenko, T.N. Zvyagintseva and I.M. Yermak (PIBOC FEB RAS) for providing samples of the polysaccharides from marine algae. This work was supported by a grant from the Russian Foundation for Basic Research (no. 04-04-08083), and by the State contract of the Ministry of science and education Russian Federation for № 16.512.11.2271.

\section{References}

[1] A.M. Popov, E.A. Popov, "The Secondary Metabolites from Herbs and Sea Invertebrates: The Biological activity and modes of action", Lambert Academic Publishing, AV Akademikerverlag GmbH \& Co. KG, Saarbrucken, Deutschland, 2012. pp. $240-330$.

[2] A.M Popov, T.I. Burtseva, I.A Lee, N.V. Semenova, E.P. Kozlovskaya, "The Effects of Balm "Herbamarin" on Functional Condition of Cardiovascular and Hepatobiliary Systems", Biomed. Chem., 2003, vol. 49, pp. 394-400.

[3] I.A. Li, A.M. Popov, A.V. Tsybul'skiı̌, N.M. Sanina, et al., "Immunostimulatory Characteristics of a Novel Carrier on the Basis of Cucumarioside A2-2 and Monogalactosyldiacylgycerol", Prikl. Biokhim. Mikrobiol., 2008, vol. 44, pp. 694-700.

[4] A. Tsybulsky, N. Sanina, I. Lee, A. Popov, E Kostetsky., O. Portnyagina, V. Shnyrov, "The Development of a New Adjuvant Lipid-Saponin Complex and its Use at Experimental Immunization by Bacterial Antigen", Biochemistry (Moscow) Supplemental Series B: Biomedical Chemistry. 2007, vol. 1, pp. 353-358.
[5] S. Bordbar, F. Anwar, N. Saari, "High-Value Components and Bioactives from Sea Cucumbers for Functional Foods. A Review," Mar. Drugs, 2011, vol. 9, pp. 1761-1805.

[6] I. Wijesekara, S.-K. Kim, "Angiotensin-I-Converting Enzyme (ACE) Inhibitors from Marine Resources: Prospects in the Pharmaceutical Industry", Mar. Drugs, 2010, vol. 8, pp. 1080-1093.

[7] A. M. Popov, A. A. Artyukov, O. N. Krivoshapko, Yu. P. Shtoda, T. A. Rutskova, V. P. Glazunov, E. P. Kozlovskaya, "Polyfunctional Pharmacological Properties of Collagen Peptides from Marine Echinoderms", Rus. J. Biopharm., 2012, vol. 4, pp. 5-16.

[8] A. M. Popov, A. A. Artyukov, V. P. Glazunov, E. V. Mandron, O. N. Krivoshapko, and E. P. Kozlovskaya, "Antitumor and Anticoagulant Activities of Collagen Protein from the Holothurian Apostichopus japonicas Modified by Proteolytic Enzymes", Rus. J. Marine Biology, 2011, vol. 37, pp. $217-222$.

[9] T. Boehm, J. Folkman, T. Browder, and M.S. O'Reilly, "Antiangiogenic Therapy of Experimental Cancer does not Induce Acquired Drug Resistance”, Nature, 1997, vol. 390, pp. $404-407$.

[10] M.V. Karamouzis, and S.J. Moschos, "The Use of Endostatin in the Treatment of Solid Tumors", Expert Opin. Biol. Ther., 2009 , vol. 9, pp. 641-648.

[11] S.M. Smorenburg, and C.J.F. van Noorden, "The Complex Effects of Heparins on Cancer Progression and Metastasis in Experimental Studies", Pharmacol. Rev., 2001, vol. 53, pp. 93-105.

[12] T.A. Kuznetsova, T.S. Zaporozhets, N.N. Besednova, et al., "Immunostimulating and Anticoagulating Activity of Fucoidan from the Brown Alga Fucus evanescens from the Sea of Okhotsk", Antibiotiki i khimoterapiya, 2003, vol. 48, pp. $11-13$.

[13] J.L. Dreyfuss, C.V. Regatieri, M.A. Lima, et al., "A Heparin Mimetic Isolated from a Marine Shrimp Suppresses Neovascularization", J. Thromb. Haemost., 2010, vol. 8, pp. $1828-1837$.

[14] Z. Li, H. Wang, J. Li, et al., "Basic and Clinical Study on the Antithrombotic Mechanism of Glycosaminoglycan Extracted from Sea Cucumber", Chin. Med. J. (Engl.), 2000, vol. 113, pp. 706-711.

[15] S. Lordan, R.P. Ross, and C. Stanton, "Marine Bioactives as Functional Food Ingredients: Potential to Reduce the Incidence of Chronic Diseases", Mar. Drugs, 2011. v. 9. P. $1056-1100$.

[16] R. Yang, J. Wang, Z. Liu, et al., “Antioxidant Effect of a Marine Oligopeptide Preparation from Chum Salmon (Oncorhynchus keta) by Enzymatic Hydrolysis in Radiation Injured Mice”, Mar. Drugs. 2011, vol. 9, pp. 2304-2315.

[17] H. Meisel, "Food-Derived Bioactive Proteins and Peptides as Potential Components of Nutraceuticals", Curr. Pharm. Des., 2007, vol. 13, pp. 873-874.

[18] T. N. Demidova-Rice, A. Geevarghese, and I. M. Herman, "Bioactive Peptides Derived from Vascular Endothelial Cell Extracellular Matrices Promote Microvascular Morphogenesis and Wound Healing in vitro", Wound Repair Regen., 
2011, vol. 19, pp. 59-70.

[19] L.Yu. Savvateeva, M.G. Maslova, and V.L. Volodarsky, Dal'nevostochnye goloturii i astsidii kak tsennoe pishchevoe syr'e (Far-Eastern Holothurians and Ascidians as a Valuable Raw Material), Vladivostok: Izt. Dal. Vost. Gos. Univ., 1983.

[20] A. Prange, H. Boddeker, W. Michaelis, and Z. Frezenius, "Multi-element Determination of Trace Elements in Whole Blood and Blood Serum by TXRF", Anal. Chem., 1989, vol. 335, pp. 914-918.

[21] F.R. Brown, A. di Corato, G.P. Lorenzi, and E.R. Blout, "Synthesis and Structural Studies of Two Collagen Analogues: Poly (L-Prolyl-L-Seryl-Glycyl) and Poly (L-Prolyl-L-Alanyl-Glycyl)", J. Mol. Biol., 1972, vol. 63, pp. 85-99.

[22] T.C. Miller, M.R. Joseph, G.J. Havrilla, et al., "Capillary Electrophoresis Micro X-Ray Fluorescence: A Tool for Benchtop Elemental Analysis", Anal. Chem., 2003, vol. 75, pp. 2048-2053.

[23] E.E. Gilbert, "Sulfonation and Related Reactions", New York: Interscience, 1965. Translated under the title Sulfirovanie organicheskikh soedinenii, Moscow: Khimiya, 1969.

[24] Z.P. Sofyina, A.B. Syrkin, A. Goldin, and A. Klyain, Eksperimental'nye otsenki protivoopukholevykh preparatov $\mathrm{v}$ SSSR i SShA (Experimental Assessments of Antitumor Preparations in USSR and USA), Moscow: Meditsina, 1980.

[25] Rukovodstvo po eksperimental'nomu doklinicheskomu izucheniyu novykh farmakologicheskikh veshchestv (A Manual for Experimental (Preclinical) Study of Novel Pharmacological Substances), Khabriev, R.U., Ed., Moscow: Meditsina, 2005.

[26] A.O. Barabanova, "Influence of Endogenous and Exogenous Factors on Structures and Properties of Carrageenans from the Red Algae Tichocarpus crinitus and Chondrus pinnulatus", Abstract of Cand. Sci. (Chem.) Dissertation, Pacific
Institute of Bioorganic Chemistry FEB RAS, Vladivostok, 2005 .

[27] T.N. Zvyagintseva, N.M. Shevchenko, A.O. Chizhov, et al., Water-Soluble Polysaccharides of Some Far Eastern Brown Seaweeds. Distribution, Structure, and Their Dependence on the Developmental Conditions, J. Exp. Mar. Biol. Ecol., 2003, vol. 294, pp. 1-13.

[28] S.G. Krylova, E.P. Zueva, T.G Razina, et al., "Effect of Apothrombostatin and Thiacarpin on the Efficiency of Cytostatic Therapy in Rats with Transplantable Tumor", Vestn. Dal. Vost. Otd. RAN, 2007, no. 6, pp. 111-115.

[29] T.E. Warkentin, "Bivalent Direct Thrombin Inhibitors: Hirudin and Bivalirudin", Best Pract. Res. Clin. Haematol., 2004, vol. 17, pp. 105-125.

[30] S. Koyanagi, N. Tanigawa, H. Nakagawa, et al., "Oversulfation of Fucoidan Enhances Its Antiangiogenic and Antitumor Activities", Biochem. Pharmacol., 2003, vol. 65, pp. 173-179.

[31] W. Halfter, S. Dong, B. Schurer, and G.J. Cole, "Collagen XVIII is a Basement Membrane Heparan Sulfate Proteoglycan”, J. Biol. Chem., 1998, vol. 273, pp. 25404-25412.

[32] M.S. Pereira, B. Mulloy, and P.A. Mourao, "Structure and Anticoagulant Activity of Sulfated Fucans. Comparison Between the Regular, Repetitive, and Linear Fucans from Echinoderms with the More Heterogeneous and Branched Polymers from Brown Algae", J. Biol. Chem., 1999, vol. 274, pp. 7656-7667.

[33] D.N. Menton, and A.Z. Eisen, "Cutaneous Wound Healing in the Sea Cucumber, Thyone briareus", J. Morphol., 1973, vol. 141, pp. 185-203

[34] B.D. Fredalina, B.H. Ridzwan, A.A. Abidin Zainal, et al., "Fatty Acid Compositions in Local Sea Cucumber, Stichopus chloronotus for Wound Healing", Gen. Pharmacol., 1999, vol. 33, pp. 337-340. 